\title{
The Activity of Rabies Vaccines against Genetic Clusters of Rabies Virus Circulating at the Territory of Ukraine
}

\author{
Mykola Ivanov*, Ivan Polupan and Oleg Deryabin
}

Institute of Veterinary Medcine, Kyiv, Ukraine

\section{Objective}

To identify the presence of genetic clusters of rabies virus at the territory of Ukraine and to determine the degree of activity of rabies vaccines against these genetic clusters.

\section{Introduction}

To develop and implement an effective program of rabies eradication in Ukraine in 2008 was founded the unique collection of samples of pathological materials confirmed as positive in rabies at the regional veterinary laboratories of Ukraine. The collection is constantly updated and to present moment it includes 1389 samples from all regions of Ukraine, selected from 17 animal species and humans.

\section{Methods}

Identification of the rabies virus in samples of pathological material for their further selection was carried out using the test developed by us which based on RT-PCR with primers complementary to the conservative fragments of the 5'-end of nucleoprotein gene of rabies virus.

For the study of the street rabies virus isolates from the collection we use RT-PCR with the primers pair $(509,304)$ flanking the variable 3 '-end part of nucleoprotein gene of the reference strain of rabies virus CVS (fragment in $377 \mathrm{bp}$ ).

Studies of rabies vaccines activity were carried out with modified method of U.S. National Institutes of Health using rabies virus street isolates of both genetic clusters instead of the Challenge Virus Standard (CVS). All isolates of street rabies virus were inoculated in a dose of $5-50 \mathrm{LD}_{50}$. The criteria for evaluation of protective activity of rabies vaccine was effective dose $\left(-\lg \mathrm{ED}_{50}\right)$.

\section{Results}

In molecular genetic studies with variant-specific primers we established the presence in Ukraine of two clusters of rabies virus. Clusters I circulates on the right bank of the Dnipro river (the largest water barrier that divides the country into eastern and western side), and cluster II - on the left bank of the Dnieper.
The relationship of these variants with the epizootic situation was researched. For this purpose epizootological zoning of Ukraine according to the intensity of the epizootic situation in 2005-2009 was carried out. As a result of this analysis all the regions of Ukraine belong to three categories: high, medium and low epizootic situation intensity of rabies.

The projection of differentiated genetic clusters on the epizootic situation showed that cluster II circulating at Left Bank of the Dnieper in areas with high and medium intensity of the epizootic situation, and the cluster I - at the Right Bank of the Dnieper, mainly in the areas with low intensity of the epizootic situation.

That's why our interest was in the degree of protection of rabies vaccines against street rabies virus isolates belonging to these two genetic clusters.

The commercial vaccines made with rabies virus vaccine strains SAD (Street-Alabama-Dufferin) and Wistar PM/WI were chosen to evaluate this parameter.

After the mathematical calculations of effective dose and the analysis of the data the less effective protection of rabies vaccines (at 29-30 \%) against street rabies virus isolates belonging to cluster II in comparison with isolates belonging to cluster I irrespective to the strain vaccine is made was shown.

\section{Conclusions}

The data will be used for the effective planning of specific prophylaxis of rabies in Ukraine based on differentiated approach to distribution of rabies vaccines in according to region and their activity.

\section{Keywords}

rabies vaccine; vaccine activity; street rabies virus isolates; genetic variants of rabies virus

*Mykola Ivanov

E-mail: IvanovNY@gmail.com 